\title{
Comportamento ingestivo de equinos em pastagens com Panicum maximum Jacq. na região do semiárido de Minas Gerais
}

\author{
[Ingestive behavior of horses in Panicum pastures at the semi-arid region of Minas Gerais]
}

\section{"Artigo Científico/Scientific Article"}

\author{
Camila Lima Sá ${ }^{1}$, Maria Dulcinéia Costa ${ }^{2 *}$, Virgilio Mesquita Gomes ${ }^{2}$, \\ Cinara Cunha Siqueira Carvalho ${ }^{2}$, José Reinaldo Mendes Ruas ${ }^{2}$, Gislane Evangelista Bispo ${ }^{3}$, \\ Wemerson Fábio Gomes Ribas ${ }^{1}$, Wagner Sousa Alves ${ }^{1}$
}

\begin{abstract}
${ }^{1}$ Curso de Zootecnia, Bolsista PIBIC/CNPq/Unimontes, Janaúba-MG, Brasil.
${ }^{2}$ Programa Pós-Graduação em Zootecnia, Bolsista FAPEMIG - Unimontes, Janaúba-MG, Brasil.

${ }^{3}$ Programa de Pós-graduação em Zootecnia, Bolsista CAPES - Unimontes, Janaúba-MG, Brasil.

*Autor para correspondência/Corresponding author: E-mail: dulcineia.costa@unimontes.br
\end{abstract}

\begin{abstract}
Resumo
Foi conduzido um experimento objetivando-se avaliar o comportamento ingestivo de equinos sob pastejo em pastagens estabelecidas com dois cultivares de Panicum maximum Jacq., cv. BRS Zuri e cv. Mombaça, em condições do semiárido mineiro. O delineamento utilizado foi o inteiramente casualizado com dois pastos representando os tratamentos, cada um com quatro repetições. O período experimental teve duração de 45 dias, sendo 17 dias de adaptação e quatro dias para avaliações do comportamento em pastejo de 10 éguas solteiras, realizadas durante 24 horas a cada 10 minutos, com intervalos de sete dias entre elas. Foram aferidos além dos tempos em pastejo diurno, noturno e diário, tempos total em ócio diurno, noturno e diário, a taxa e número de bocados diários, a estrutura morfológica e a composição químico-bromatológica dos pastos. No cv. BRS Zuri constatou-se maiores proteína bruta $(11,76 \%)$, densidade volumétrica de folhas $(208,91 \mathrm{~kg} / \mathrm{ha} . \mathrm{cm}$ MS) e taxa de bocado diário (35,10 bocado/minuto), enquanto que no cv. Mombaça observou-se maiores teores de matéria seca $(39,16 \%)$, FDN $(71,85 \%)$ e altura do pasto $(61,75 \mathrm{~cm})$. Porém, isso não provocou diferença entre os tempos em pastejo e ócio diurno, noturno e diário, das éguas. Éguas solteiras dispendem o mesmo tempo em pastejo sob temperaturas do ar elevadas independente dos cultivares de Panicum maximum Jacq. embora estas apresentem estruturas morfológicas diferentes.
\end{abstract}

Palavras-chave: cavalo; tempo em pastejo; tempo em ócio; taxa de bocados.

\begin{abstract}
This study was carried out in order to evaluate the ingestive behavior of equines in pastures of two Panicum maximum Jacq. cultivars, BRS Zuri grass and Mombaça grass, in the semi-arid region of Minas Gerais. A completely randomized design with two pastures representing the treatments, each with four replicates, was used. The experimental period lasted 45 days, with 17 days for adaptation of grazing behavior of ten single mares, performed for 24 hours every ten minutes, with intervals of seven days between them. In addition to the times of day, night, and daily pasture, the rate and number of daily bites, morphological structure, and chemical composition of pastures were measured. In cv. BRS Zuri grass, there were higher levels of crude protein $(11.76 \%)$, leaf volumetric density $(208.91 \mathrm{~kg} / \mathrm{ha} . \mathrm{cm}$ dry matter) and daily biting rate (35.10 bites/minute), while the highest values for cv. Mombaça grass were for dry matter (39.16\%), neutral detergent fiber $(71.85 \%)$ and height $(61.75 \mathrm{~cm})$. However, this did not cause any difference between grazing times and daytime, nighttime, and daily idleness of the mares. Single mares spend the same time grazing under elevated air temperatures independent of Panicum maximum Jacq cultivars although these have different morphological structures.
\end{abstract}

Keywords: horse; grazing time; leisure time; biting rate. 


\section{Introdução}

O comportamento dos equinos em pastejo é influenciado por fatores internos e externos. Entre os fatores externos podem ser citados o clima, estação do ano, manejo, estrutura do pasto, disponibilidade e digestibilidade das forrageiras, dentre outros. Enquanto os fatores internos incluem-se seletividade, requerimentos nutricionais de acordo com a categoria animal, tamanho e frequência do bocado, idade, sexo e reconhecimento espacial do pasto pelo animal (Dittrich et al., 2007a; Dittrich et al., 2007b). De acordo com Zanine et al. (2009) éguas, cavalos e mulas diferem no comportamento ingestivo sob pastejo que pode estar relacionado com a energia de mantença ou produtiva de cada categoria. Da mesma forma, a distribuição das características estruturais do pasto como altura, densidade volumétrica e componentes como folha, colmo e inflorescência no estrato vertical da vegetação também interferem nesta seleção (Dittrich et al., 2005; Dittrich et al., 2007a; Dittrich et al., 2007b) tornando possível a remoção pelo animal por meio do bocado. O aporte de nutrientes é dependente das estruturas das forragens (Dittrich et al., 2010) e é variável com as condições ambientais (Johnson et al., 2001). Portanto, faz-se necessário conhecer a composição químico-bromatológica das pastagens e sua relação com os hábitos de pastejo em equinos. Além disso, a associação dos fatores climáticos como temperatura, umidade relativa do ar e radiação solar provocam alterações fisiológicas que comprometem o bem-estar e, consequentemente, alterações no comportamento alimentar (Johnson et al., 2001). Na região do semiárido, a temperatura e umidade relativa do ar, índices pluviométricos e radiação solar alcançam valores elevados. Esses fatores climáticos, quando associados ao manejo inadequado do animal e da pastagem, podem ser considerados elementos estressantes e refletirem negativamente no desempenho animal, além de impedir a exteriorização do seu potencial produtivo e reprodutivo.

Assim, objetivou-se com esta pesquisa, avaliar características estruturais e composição químico-bromatólogica de pastagens estabelecidas com dois cultivares de Panicum maximum Jacq., cv. Mombaça e cv. BRS Zuri e seu efeito no comportamento ingestivo de equinos em condições semiáridas.

\section{Material e Métodos}

$\mathrm{O}$ experimento foi conduzido em propriedade particular, município de Janaúba, Minas Gerais, inserida no semiárido mineiro, cujo clima predominante na região é o tropical megatérmico (Aw) caracterizado por longos períodos de seca e veranicos frequentes dentro do curto período chuvoso (Antunes, 1994). O delineamento experimental utilizado foi $\mathrm{o}$ inteiramente casualizado com dois tratamentos (cultivares de Panicum maximum Jacq.: cv. Mombaça e cv. BRS Zuri) com 04 repetições (piquetes). Foram utilizados quatro piquetes com área média de $5491 \mathrm{~m}^{2}$ sendo dois piquetes estabelecidos com cv. Mombaça e dois com cv. BRS Zuri, com distância entre os mesmos de aproximadamente $500 \mathrm{~m}$ e irrigados por sistema de aspersão convencional. Antes da entrada dos animais em cada piquete de cada cultivar foram coletadas amostras para estimativa da forragem disponível. Utilizou-se o método direto coletandose no pré-pastejo a intervalos de 7 dias, em quatro pontos representativos da condição média do pasto, por meio do lançamento de uma moldura metálica de $0,25 \mathrm{~m}^{2}$. Toda forragem contida dentro da moldura foi cortada manualmente com auxílio de uma tesoura de poda, acondicionada em sacos plásticos, pesada e homogeneizada. Posteriormente, no laboratório, foi retirada uma subamostra para determinação do teor de matéria seca (MS) conforme procedimentos descritos por Detmann et al. (2012). O restante do material foi separado em seus componentes: lâminas foliares, colmos e material morto também expressos em MS. De posse dessas informações foi possível determinar as produções de matéria seca de forragem total, de lâminas foliares, de colmo e material morto (expressos em kg.ha- ${ }^{-1}$ de MS). A relação lâmina foliar/colmo (RLC) foi obtida por meio da razão entre a produção de MS de lâmina foliar e a produção de MS de colmo, de forma semelhante obteve-se a relação material vivo/material morto (RMVMM). A densidade volumétrica de forragem total $\left(\mathrm{kg} \cdot \mathrm{ha}^{-1} \cdot \mathrm{cm}\right.$ de MS) foi obtida pela razão entre a produção de MS total de forragem e a altura $(\mathrm{cm})$ média das plantas no momento do corte. Foi determinada a composição químico-bromatológica da amostra de forragem total provenientes de cada pasto, determinando-se os teores de proteína bruta (PB) e fibra em detergente neutro (FDN) seguindo procedimentos descritos por Detmann et al. (2012). Após a coleta das amostras dos capins, os piquetes de cada 
cultivar foram pastejados por 05 éguas solteiras, durante o período de dois dias, com intervalo de descanso de 7 dias entre os pastejos. Logo após a retirada dos animais os piquetes foram irrigados com a mesma lâmina de irrigação proporcionando condições similares de rebrotação. A altura dos pastos foi monitorada antes da entrada dos animais nos piquetes por meio da mensuração de 30 pontos aleatórios, percorrendo-se todo o piquete em zigzag, utilizando-se régua graduada em centímetros. Foram aferidas a temperatura do ar a cada hora durante 24 horas, utilizando um termômetro de máxima e de mínima instalados em cada piquete.

Antes de iniciar o experimento, como os piquetes eram utilizados pelos animais da propriedade sob pastejo em lotação contínua, todos os animais foram retirados dos pastos 30 dias antes do período experimental para que a forragem fosse irrigada e apresentasse condições experimentais para a coleta dos dados. O período experimental teve duração de 45 dias, sendo 17 dias de adaptação e quatro dias para avaliações do comportamento dos animais em pastejo, com intervalos de sete dias entre elas, realizadas durante 24 horas diuturnamente, obtidas por meio de observações visuais dos animais realizadas a cada 10 minutos. Para avaliação do comportamento ingestivo foram utilizadas 10 éguas solteiras sem raça definida, com média de idade de 8 anos, peso médio de $482 \mathrm{~kg}$, vermifugadas antes do início do período experimental. Na primeira avaliação utilizou-se dois piquetes, sendo um do cv. Mombaça e outro do cv. BRS Zuri, onde sorteou-se aleatoriamente cinco éguas para pastejo em cada piquete. Após a primeira coleta dos dados, os animais foram mudados de piquete, porém, permanecendo em pastejo no mesmo cultivar, de modo que cada piquete passasse por duas avaliações com intervalo entre uma e outra de 14 dias. Neste intervalo, período de descanso sem pastejo, foram irrigadas para estimular a rebrotarão e obter total recuperação das plantas.

Os tempos em pastejo e ócio foram obtidos por meio de observações visuais dos animais realizadas a cada 10 minutos durante 24 horas, conforme metodologia descrita em Hodgson (1985), nos períodos diurno compreendido entre os horários de 07:00 às 19:00h, e o período noturno entre 19:00 e 07:00h e o diário considerando as $24 \mathrm{~h}$.

A taxa de bocados foi obtida por meio da contagem direta do número de bocados, quantificado visualmente por dois observadores para cada animal, no período de um minuto sendo a resultante da média de observações feitas durante 30 minutos com auxílio de um cronômetro no período da manhã e da tarde, adaptando metodologia descrita por Santos et al. (2006).

Os dados referentes aos tempos em pastejo, em ócio, e a taxa e número de bocados diários observados nos equinos, as análises químicobromatológicas dos cultivares e a temperatura do ar foram submetidos à análise de variância e as médias comparadas pelo teste SNK a 5\% de probabilidade.

\section{Resultados e Discussão}

A estrutura morfológica do pasto do cv. BRS Zuri foi caracterizada por maior $(\mathrm{P}<0,05)$ densidade volumétrica de folha $\left(208,91 \mathrm{~kg}\right.$. ha ${ }^{-1} . \mathrm{cm}$ de MS $)$ e menor $(\mathrm{P}<0,05)$ altura das plantas $(45,56$ $\mathrm{cm})$ o que refletiu em um menor $(\mathrm{P}<0,05)$ teor de MS $(26,76 \%)$ e maior $(\mathrm{P}<0,05)$ percentual de $\mathrm{PB}$ $(11,76 \%)$ quando comparado ao pasto do cv. Mombaça (Tabela 1). As características estruturais das plantas, como altura e a densidade dos seus componentes como folha, são importantes componentes a serem identificados pois, interferem na seleção da dieta pelos equinos (Dittrich et al., 2005) e determinam a probabilidade dos seus componentes serem removidos pelo animal na realização de um bocado. Em pastagens cultivadas e livres de contaminação prévia por fezes, de acordo com Dittrich et al. (2010), a escolha dos equinos é por plantas e dosséis mais altos, demonstrada pelo maior tempo de pastejo nos dosséis de maior altura e por seleção de plantas mais altas, individualmente, os quais proporcionam maior dimensão de forragem colhida a cada bocado (Dittrich et al., 2005). Porém, como o principal componente da estrutura das plantas (folhas) refletem também a qualidade do alimento colhido pelo cavalo, as maiores DVF observadas no pasto do cv. BRS Zuri refletiram em seus maiores percentuais de PB, já que as folhas, de forma geral, são mais ricas em nitrogênio do que os colmos dos capins. A diferença observada nos teores de MS nos pastos dos diferentes cultivares (Tabela 1), maior $(\mathrm{P}<0,05)$ no $\mathrm{cv}$. BRS Zuri em detrimento do cv. Mombaça, também é um fator importante de ser observado na avaliação de gramíneas para o pastejo de equinos. Pois, considerando-se que um menor teor de MS implica em maior umidade na planta, ou seja, sendo mais tenra que aquelas com menos água em sua composição, possibilita maior facilidade de remoção, mastigação e deglutição, 
implicando em menores limitações como a menor

digestibilidade destes tecidos (O’Reagain e força de tração necessária para sua colheita, bem Schwartz, 1995).

como limitações causadas pela menor

Tabela 1. Média da composição químico-bromatológica e características estruturais de acordo com o tratamento

\begin{tabular}{lcc}
\hline \multirow{2}{*}{ Composição químico-bromatológica } & \multicolumn{2}{c}{ Tratamento } \\
\cline { 2 - 3 } & cv. BRS Zuri & cv. Mombaça \\
\hline Proténa Bruta (\%MS) & $11,76 \mathrm{a}$ & $6,44 \mathrm{~b}$ \\
Fibra em detergente neutro (\%MS) & $67,59 \mathrm{~b}$ & $71,85 \mathrm{a}$ \\
Matéria seca (\%MS) & $26,76 \mathrm{~b}$ & $39,16 \mathrm{a}$ \\
Densidade Volumétrica de Folha (kg/ha.cm MS) & $208,91 \mathrm{a}$ & $113,25 \mathrm{~b}$ \\
Relação Lâmina/Colmo & $1,61 \mathrm{a}$ & $1,62 \mathrm{a}$ \\
Relação Matéria Verde/Matéria Morta & $2,96 \mathrm{a}$ & $3,28 \mathrm{a}$ \\
Colmo verde (kg/ha.MS) & $2625,8 \mathrm{a}$ & $2152,1 \mathrm{a}$ \\
Folha verde (kg/ha.MS) & $3858,6 \mathrm{a}$ & $2481,0 \mathrm{a}$ \\
Material Morto (kg/ha.MS) & $2887,5 \mathrm{a}$ & $2341,9 \mathrm{a}$ \\
Forragem Total (kg/ha.MS) & $9372,0 \mathrm{a}$ & $6975,0 \mathrm{a}$ \\
Altura $(\mathrm{cm})$ & $45,56 \mathrm{~b}$ & $61,75 \mathrm{a}$ \\
\hline
\end{tabular}

MS = Matéria seca. *Médias seguidas pela mesma letra na linha não diferem estatisticamente pelo teste SNK a 5\% de probabilidade.

Houve diferença na temperatura do ar (Tar) entre os turnos noturno e diurno entre os pastos do cv. BRS Zuri e cv. Mombaça (Tabela 2) que apresentaram média diária de $21,0^{\circ} \mathrm{C}$ e $22,0^{\circ} \mathrm{C}$ e noturna de $15,0^{\circ} \mathrm{C}$ e $17,0^{\circ} \mathrm{C}$, respectivamente. Isto pode ser explicado pela heterogeneidade do ambiente, uma vez que, logo ao lado dos pastos formados com cv. BRS Zuri havia tanques para criação de peixe, o que possivelmente influenciaram os elementos climáticos.

Com relação aos horários do dia, observase (Tabela 3) que os maiores valores de Temperatura do ar (Tar) foram verificados entre os horários das 13:00h às $16: 00 \mathrm{~h}$ em torno de $31,5^{\circ} \mathrm{C}$ nos dois pastos e, no período noturno atingiu 11,1 e $13,4^{\circ} \mathrm{C}$ para o cv. BRS Zuri e cv. Mombaça, respectivamente.

Não foram encontradas diferenças significativas $(\mathrm{P}=0,534)$ nos tempos em pastejo das éguas nos pastos do cv. BRS Zuri e do cv. Mombaça, porém, houve efeito significativo $(\mathrm{P}<0,05)$ do horário do dia nos tempos em pastejo (Tabela 3). Observa-se que as éguas pastejaram em maior ou menor intensidade durante todo o dia despendendo maior tempo em pastejo no horário de 07:00h até 10:00h onde constatou-se temperatura média do ar de $24^{\circ} \mathrm{C}$. A partir das 10:00 até às 19:00h os tempos em pastejo foram similares, mas de menor intensidade mesmo com temperatura acima de $27^{\circ} \mathrm{C}$, sendo que as éguas retornaram ao pastejo às $04: 00 \mathrm{~h}$ e permaneceram até $07: 00 \mathrm{~h}$ da manhã seguinte quando a temperatura média do ar
Tabela 2. Médias da temperatura do ar $\left({ }^{\circ} \mathrm{C}\right)$ nos períodos diurno, noturno e diário de acordo com o tratamento

\begin{tabular}{lccc}
\hline \multirow{2}{*}{ Tratamento } & \multicolumn{3}{c}{ Períodos } \\
\cline { 2 - 4 } & *Diurno & Noturno & Diária \\
\hline cv. BRS Zuri & $28,0 \mathrm{a}$ & $15,0 \mathrm{a}$ & $21,0 \mathrm{a}$ \\
cv. Mombaça & $28,0 \mathrm{a}$ & $17,0 \mathrm{~b}$ & $22,0 \mathrm{~b}$ \\
CV $(\%)$ & 1,00 & 1,57 & 1,11 \\
\hline
\end{tabular}

*Médias seguidas pela mesma letra na linha não diferem estatisticamente pelo teste SNK a $5 \%$ de probabilidade.

$* \mathrm{CV}=$ coeficiente de variação

atingiu $11^{\circ} \mathrm{C}$. As éguas pastejaram menor tempo nos horários de 19:00h até 4:00h quando entraram em ócio (Tabela 4). Em estudos realizados com equinos mantidos em condições naturais de pastejo em climas tropicais, observou-se uma diminuição no consumo de alimentos no período entre 23:00 e 04:00 horas (Santos et al., 2006; Zanine et al., 2006), semelhante ao encontrado. Waring (1975) relatou que os equinos pastejam menos nos horários mais quentes do dia, bem como no final da madrugada, sendo esses os horários em que geralmente os animais dormem, o que não foi verificado nesse trabalho. Nos horários mais quentes do dia os animais diminuíram o pastejo mas não entraram em ócio (Tabela 4). Possivelmente isso ocorreu devido à condição fisiológica dos animais utilizados, éguas solteiras, para suprir as suas necessidades nutricionais (Zanine et al., 2006; Zanine et al., 2009). Portanto, uma alternativa para amenizar esta condição seria arborizar as áreas de pastejo oferecendo situação de 
conforto e bem-estar para os animais nas horas mais quentes do dia, nas regiões do semiárido.

Os cultivares de Panicum maximum Jacq. não tiveram efeito $(\mathrm{P}=0,548)$ no tempo em ócio dos animais (Tabela 4). Da mesma forma que no tempo em pastejo houve efeito dos horários do dia $(\mathrm{P}<0,05)$ com maior tempo em ócio no período noturno de 19:00h as 22:00h e 01:00 as 04:00h $(\mathrm{P}<0,05)$, períodos estes onde foram observadas as temperaturas mais amenas (Tabela 4). Vieira et al. (2006) em experimento na Bahia, utilizando pastagens formadas de capim Coast-cross (Cynodon ssp.), observaram que os equinos permaneceram maior tempo em ócio entre as 16:00h e 19:00h e no final da madrugada, a partir de 1:00h até as 4:00h, quando verificou-se decréscimo da temperatura do ar nos pastos. Os autores afirmaram que pode ter sido influenciado pela temperatura ambiental e estrutura do pasto. Provavelmente a justificativa que melhor poderia explicar este comportamento é a de que, sendo os equinos essencialmente noturnos, instinto este herdado de cavalos selvagens, por serem presas na natureza, mantêm maior tempo em ócio durante o período noturno (Resende et al., 2006). Deste modo observa-se que, após o pastejo, os animais entraram em ócio, com o objetivo de direcionar o metabolismo para a digestão dos alimentos ingeridos. Assim, observou-se comportamento antagônico entre o tempo de pastejo e ócio (Silva et al., 2015).

Tabela 3. Médias do tempo em pastejo (T. pastejo) de equinos e da temperatura do ar (Tar) em diferentes horários do dia de acordo com o tratamento

\begin{tabular}{|c|c|c|c|c|c|}
\hline \multirow{3}{*}{ Horário } & \multicolumn{4}{|c|}{ Tratamento } & \multirow{3}{*}{$\begin{array}{c}\text { Média* } \\
(\mathrm{P}<0,0001)\end{array}$} \\
\hline & \multicolumn{2}{|c|}{ cv. BRS Zuri } & \multicolumn{2}{|c|}{ cv. Mombaça } & \\
\hline & $\operatorname{Tar}\left({ }^{\circ} \mathrm{C}\right)$ & T. pastejo (hora) & $\operatorname{Tar}\left({ }^{\circ} \mathrm{C}\right)$ & T. pastejo (hora) & \\
\hline $07-10$ & 24,1 & 2,63 & 24,4 & 2,79 & $2,71 \mathrm{~A}$ \\
\hline $10-13$ & 29,7 & 2,37 & 30,2 & 2,00 & $2,18 \mathrm{ABC}$ \\
\hline $13-16$ & 31,5 & 2,33 & 31,6 & 2,21 & $2,27 \mathrm{AB}$ \\
\hline $16-19$ & 27,8 & 2,25 & 27,9 & 2,41 & $2,33 \mathrm{AB}$ \\
\hline $19-22$ & 17,5 & 1,58 & 19,6 & 1,79 & $1,69 \mathrm{C}$ \\
\hline $22-01$ & 16,4 & 2,19 & 18,7 & 1,71 & $1,95 \mathrm{C}$ \\
\hline 01-04 & 13,9 & 1,56 & 15,2 & 1,71 & $1,63 \mathrm{C}$ \\
\hline 04-07 & 11,1 & 2,46 & 13,4 & 2,21 & $2,33 \mathrm{AB}$ \\
\hline Média $(\mathrm{P}=0,534)$ & & $2,17 \mathrm{a}$ & & $2,10 \mathrm{a}$ & \\
\hline
\end{tabular}

*Médias seguidas pela mesma letra maiúscula na coluna e minúscula na linha não diferem estatisticamente pelo teste SNK a 5\% de probabilidade.

Tabela 4. Médias do tempo em ócio (T.ócio) de equinos e da temperatura do ar (Tar) em diferentes horários de acordo com o tratamento

\begin{tabular}{|c|c|c|c|c|c|}
\hline \multirow{3}{*}{ Horário } & \multicolumn{4}{|c|}{ Tratamento } & \multirow{3}{*}{$\begin{array}{c}\text { Média* } \\
(\mathrm{P}<0,0001)\end{array}$} \\
\hline & \multicolumn{2}{|c|}{ cv. BRS Zuri } & \multicolumn{2}{|c|}{ cv. Mombaça } & \\
\hline & $\operatorname{Tar}\left({ }^{\circ} \mathrm{C}\right)$ & T.ócio (hora) & $\operatorname{Tar}\left({ }^{\circ} \mathrm{C}\right)$ & T.ócio (hora) & \\
\hline $07-10$ & 24,1 & 0,37 & 24,4 & 0,21 & $0,29 \mathrm{C}$ \\
\hline $10-13$ & 29,7 & 0,62 & 30,2 & 1,00 & $0,81 \mathrm{ABC}$ \\
\hline $13-16$ & 31,5 & 0,67 & 31,6 & 0,79 & $0,73 B \mathrm{~B}$ \\
\hline $16-19$ & 27,8 & 0,75 & 27,9 & 0,58 & $0,67 \mathrm{BC}$ \\
\hline $19-22$ & 17,5 & 1,42 & 19,6 & 1,21 & $1,31 \mathrm{~A}$ \\
\hline $22-01$ & 16,4 & 0,81 & 18,7 & 1,27 & $1,04 \mathrm{AB}$ \\
\hline 01-04 & 13,9 & 1,44 & 15,2 & 1,29 & $1,36 \mathrm{~A}$ \\
\hline 04-07 & 11,1 & 0,54 & 13,4 & 0,79 & $0,66 \mathrm{BC}$ \\
\hline Média $(\mathrm{P}=0,548)$ & & $2,17 \mathrm{a}$ & & $2,10 \mathrm{a}$ & \\
\hline
\end{tabular}

*Médias seguidas pela mesma letra maiúscula na coluna e minúscula na linha não diferem pelo teste SNK a 5\% de probabilidade.

Zanine et al. (2006), avaliando éguas paridas, éguas gestantes e cavalos inteiros, observaram que em ambas as categorias, o tempo em ócio foi maior por volta do meio dia, provavelmente pela ocorrência de maior temperatura e, no final da noite, após os picos de pastejo.
Os tempos em pastejo diurno, noturno e diário não foram influenciados $(\mathrm{P}<0,05)$ pelos diferentes pastos utilizados (Tabela 5). Quando os animais têm acesso ao pasto ad libitum pastejam frequentemente durante o dia e à noite (Bott et al., 2013). Esses resultados corroboram com o encontrado por Santos et al. (2006), que avaliando o comportamento ingestivo de equinos em 
pastagens de Paspalum notatum e Brachiaria decumbens, não verificaram diferenças nos tempos em pastejo diário independentemente da espécie forrageira, com períodos de pastejo de $14,08 \mathrm{~h}$ e $13,30 \mathrm{~h}$ respectivamente.

Tabela 5. Tempo em pastejo (hora/dia) dos equinos nos períodos diurno, noturno e diário no semiárido, de acordo com o tratamento

\begin{tabular}{llll}
\hline Tratamento & Diurno & Noturno & Diário \\
\hline cv. BRS Zuri & 9,58 & 7,79 & 17,75 \\
cv. Mombaça & 9,41 & 7,79 & 17,20 \\
CV $(\%)^{*}$ & 4,17 & 2,13 & 5,26 \\
\hline
\end{tabular}

$*_{\mathrm{CV}}=$ coeficiente de variação

Não houve diferença para o tempo total em pastejo. Infere-se que as éguas não promoveram adequação no tempo em pastejo como forma de compensar o seu comportamento mais seletivo uma vez que os pastos possuíam características estruturais semelhantes. De acordo com Santos et al. (2006) o tempo destinado ao pastejo noturno não apresenta diferenças significativas do tempo em pastejo diurno, sendo que os valores encontrados mostram pequenas flutuações.

O tempo diário em pastejo variou de 17,75 a 17,20 horas nos pastos formados com cv. BRS Zuri e cv. Mombaça, respectivamente. Esses valores estão de acordo com Meyer (1995), que relatou que os equinos ingerem a forragem em pequenas e frequentes porções, durante o dia e à noite, ocupando diariamente entre 12 a 18 horas em pastejo.

Diferenças significativas não foram observadas nos tempos em ócio diurno e noturno, assim como não foi observada diferença para o tempo em ócio diário das éguas em pastejo nos dois cultivares ( $\mathrm{P}>0,05$; Tabela 6$)$.

Tabela 6. Tempo em ócio (hora/dia) dos equinos nos períodos diurno, noturno e diário de acordo com o tratamento

\begin{tabular}{lccc}
\hline \multirow{2}{*}{ Tratamento } & \multicolumn{3}{c}{ Períodos } \\
\cline { 2 - 4 } & Diurno & Noturno & Diário \\
\hline cv. BRS Zuri & 2,41 & 4,20 & 6,62 \\
cv. Mombaça & 2,58 & 4,56 & 7,14 \\
CV $(\%)$ & 15,86 & 6,04 & 9,33 \\
\hline$*$ CV $)$ coeficiente de variação & &
\end{tabular}

Santos et al. (2006) encontraram maior tempo em ócio somente no período noturno para a pastagem de $B$. decumbens $(9,08$ horas) e $P$. notatum $(5,56 \mathrm{~h})$. Diferentemente, Zanine et al. (2006) em éguas paridas, gestantes e cavalos inteiros no nordeste do Brasil, observaram que independente da categoria, o tempo em ócio foi maior por volta do meio dia, provavelmente pela maior temperatura e, no final da noite, após os picos de pastejo.

Os dois cultivares de $P$. maximum Jacq. (Tabela 7) não tiveram efeito no número de bocados diário $(\mathrm{P}>0,05)$ apesar do número de bocados por minuto, no cv. BRS Zuri $(35,09)$, ter sido superior $(\mathrm{P}<0,05)$ ao de cv. Mombaça $(31,393)$. Possivelmente essa menor taxa de bocados para cv. Mombaça pode estar associada à maior seletividade dos animais, principalmente pela menor oferta de forragem, associado a uma forrageira com teor de MS, FDN e altura mais elevados que o cv. BRS Zuri (Tabela 1). O elevado teor de FDN e MS pode ter interferido no tempo de remoção, mastigação e insalivação do bolo alimentar para ser deglutido, aumentando o intervalo de coleta de forragem entre cada bocado, o que ocasionou, consequentemente, menor número de bocados por minuto. De acordo com Dittrich et al. (2010) equinos preferem forragens com menor concentração de MS, as quais se apresentam de forma mais tenra o que proporciona maior facilidade na apreensão e mastigação. Consequentemente, a velocidade de ingestão é maior e determina rápida deglutição do bolo alimentar, o que permite que o animal retorne mais rápido a coleta da forragem.

Tabela 7. Média da taxa de bocados e total de bocados diários dos equinos de acordo com o tratamento

\begin{tabular}{lcc}
\hline Tratamento & $\begin{array}{c}\text { Taxa de bocados* } \\
\text { (bocado/minuto) }\end{array}$ & $\begin{array}{c}\text { Total de bocados } \\
\text { diário } \\
\text { (bocado/dia) }\end{array}$ \\
\hline cv. BRS Zuri & $34,85 \mathrm{a}$ & $37454 \mathrm{a}$ \\
cv. Mombaça & $31,39 \mathrm{~b}$ & $32460 \mathrm{a}$ \\
$\mathrm{CV}(\%)$ & 15,26 & 16,38 \\
\hline
\end{tabular}

*Médias seguidas pela mesma letra na coluna não diferem, estatisticamente, pelo teste SNK, $5 \%$ de probabilidade. $* \mathrm{CV}=$ coeficiente de variação

Os equinos são altamente seletivos mesmo quando gramíneas do mesmo gênero são ofertadas em pastejo, mantendo o mesmo número de bocados por dia em ambos os pastos. Estas observações demonstram potenciais diferenças no consumo entre as gramíneas, o que pode determinar melhor utilização destas forrageiras na alimentação dos equinos em pastejo. Além da composição bromatológica a estrutura das forrageiras como a altura também interfere no número de bocados, uma vez que menores alturas determinam mais bocados para uma mesma ingestão. O cv. BRS Zuri 
apresentou altura média de $45,56 \mathrm{~cm}$ quando comparado ao cv. Mombaça $(61,75 \mathrm{~cm})$.

Santos et al. (2006) avaliando comportamento ingestivo de cavalos castrados, sem raça definida no Centro-Oeste brasileiro encontraram valores da taxa de bocados/minuto de 26,76 e número diário de 22720 no pasto de $P$. notatum, enquanto no pasto de $B$. decumbens a taxa de bocados/minuto e número de bocados diário foi 21,22 e 17166, respectivamente. Valores estes inferiores ao encontrado neste trabalho, porém essa diferença pode estar relacionada às espécies de forrageiras utilizadas. Vale ressaltar que a frequência de bocados tem grande influência de fatores ambientais, estruturais e da composição do pasto, sendo mecanismo compensatório para manter a ingestão de matéria seca relativamente constante (Chacon et al., 1978).

Houve interação entre os turnos matutino e vespertino e tipo de pasto (Tabela 8 ). Independente da forrageira a taxa de bocados por minuto foi similar $(\mathrm{P}>0,05)$ nos dois turnos. Porém o mesmo não aconteceu com os tipos de pastos. O pasto com cv. BRS Zuri (17,42 bocado/minuto) obteve média superior $(\mathrm{P}<0,05)$ ao observado no pasto com cv. Mombaça (15,70 bocado/minuto). Essa diferença pode ter ocorrido devido ao menor valor de MS e FDN do cv. BRS Zuri em relação ao cv. Mombaça (Tabela 1). De acordo com Mayne et al. (2000) o animal pode compensar a menor massa de bocado com o aumento da taxa de bocados até determinado limite. Assim, o animal compensa a menor ingestão de MS por maior número de bocado (Dittrich et al., 2010).

Tabela 8. Média para taxa de bocados (bocado/minuto), nos turnos de acordo com o tratamento

\begin{tabular}{lccc}
\hline \multirow{2}{*}{ Tratamento } & \multicolumn{3}{c}{ Turno } \\
\cline { 2 - 4 } & Matutino* & Vespertino & Média \\
\hline cv. BRS Zuri & 15,97 & 18,88 & $17,42 \mathrm{~A}$ \\
cv. Mombaça & 16,43 & 14,96 & $15,70 \mathrm{~B}$ \\
Média & $16,20 \mathrm{a}$ & $16,97 \mathrm{a}$ & \\
\hline
\end{tabular}

*Médias seguidas pela mesma letra maiúscula na coluna e minúscula na linha não diferem pelo teste SNK a $5 \%$ de probabilidade.

Vieira et al. (2006) avaliaram o comportamento de 10 éguas no terço final da gestação e 10 cavalos castrados da raça Mangalarga em pastagens de Coast cross (Cynodon $s s p)$. Observaram que éguas no terço final de gestação o número de bocados por minutos foi de 28,0 e 30,0 no período diurno e noturno, respectivamente.
Dittrich et al. (2005) afirmaram que em pastagens onde a biomassa é adequada, os equinos concentram o pastejo onde a altura das plantas é maior e que em alturas menores os animais tiveram mais tempo de pastejo provavelmente associado a maior necessidade de aporte de nutrientes o que aumentou o número de bocados. De acordo com Fleurance et al. (2007) os equinos evitam forrageira alta se for de baixa qualidade químicobromatológica. Da mesma forma, se a forrageira apresentar condições bromatológicas adequadas, for de menor porte e se estiver próxima de fezes também não será consumida, o que seria uma condição de evitar a ingestão de ovos de parasitas e, consequentemente, uma parasitose. Edouard et al. (2009) encontraram média de ingestão voluntária diária de $21 \mathrm{~g} \mathrm{MS} / \mathrm{kg} / \mathrm{PV}^{-1} / \mathrm{dia}^{-1}$ e média de tempo total de pastejo de $14 \mathrm{~h} / \mathrm{dia}^{-1}$, e que eram independentes da altura da forrageira, mas de boa qualidade nutricional.

\section{Conclusão}

Éguas solteiras dispendem o mesmo tempo em pastejo sob temperaturas do ar elevadas independente dos cultivares de Panicum maximum Jacq. embora estas apresentem estruturas morfológicas diferentes.

\section{Conflito de interesse}

Os autores declaram não existir conflito de interesse.

\section{Comitê de Ética}

O projeto de pesquisa foi aprovado pelo Comitê de Ética em Experimentação e Bem-Estar Animal da Universida Estadual de Montes Claros (CEEBEA / UNIMONTES), sob o protocolo $n^{\circ}$ $141 / 17$.

\section{Agradecimentos}

À FAPEMIG e CAPES pelo apoio financeiro e ao Haras Solidão pela disponibilidade dos animais.

\section{Referências}

Antunes, F.Z. Caracterização climática. Informe Agropecuário, 17(181): 15-19, 1994.

Bott, R.C.; Greene, E.A; Kock, K.; Martinson, K.L.; Siciliano, P.D.; Williams, C.; Trottier, N.L.; Burk, A. Production and environmental implications of equine grazing. Journal Equine Veterinary Science, 33: 1031-1043, 2013 
Chacon, E.A.; Stobbs, T.H.; Dale, M.B. Influence of sward characteristics on grazing behavior and growth of Hereford steers grazing tropical grass pastures. Australian Journal of Agricultural Research, 29: 89-102, 1978.

Detmann, E.; Souza, M.A.; Vadalares Filho, S.C.; Queiroz, A.C.; Berchielli, T.T.; Saliba, E.O.S.; Cabral, L.S.; Pina, D.S.; Lacerda, M.M.; Azevedo, J.A.G. Métodos para análise de alimentos - Instituto Nacional de Ciência e Tecnologia de Ciência Animal, INCT. Visconde do Rio Branco-MG: Suprema, 2012. 214p.

Dittrich, J.R.; Carvalho, P.C.F.; Moraes, A.; Lustosa, S.B.C.; Silveira, E.O.; Oliveira, E.B. Preferência de equinos em pastejo: efeito da altura de dosséis de gramíneas do gênero Cynodon. Archives of Veterinary Science, 10(2): 61-67, 2005.

Dittrich, J.R.; Carvalho, P.C.F.; Ditrich, R.L.; Moraes, A. Comportamento ingestivo de equinos em pastagens. Archives of Veterinary Science, 12(3): 1-8, 2007a.

Dittrich, J.R.; Carvalho, P.C.F.; Moraes, A.; Oliveira, E.B.; Dittrich, R.L.; Oikawa, M.; Souza, F.T.V.; Santos, F. Comportamento ingestivo de equinos em pastejo sobre diferentes dosséis. Ciência Animal Brasileira, 8(1): 87-94, $2007 \mathrm{~b}$.

Dittrich, J.R.; Melo, H.A.; Afonso, A.M.C.F.; Dittrich, R.L. Comportamento ingestivo de equinos e a relação com o aproveitamento das forragens e bem-estar dos animais. Revista Brasileira de Zootecnia, 39: 130-137, 2010.

Edouard, N.; Fleurance, G.; Dumont, B.; Baumont, R.; Duncan, P. Does sward height affect feeding patch choice and voluntary intake in horses? Applied Animal Behaviour Science, 119: 219-228, 2009.

Fleurance, G.; Duncan, P.; Fritz, H; Cabaret, J.; Cortet, J.; Gordon, I.J. Selection of feeding sites by horses at pasture: Testing the antiparasite theory. Applied Animal Behaviour Science, 108: 288-30, 2007.

Hodgson, J. Ingestive behaviour. In: Leaver, J.D. (Ed) Herbage intake handbook. Wallingford: The British Grassland Society, 1985. p.113-138.

Johnson, C.R.; Reiling, B.A.; Mislevy, P.; Hall, M.B. Effects of nitrogen fertilization and harvest date on yield, digestibility, fiber, and protein fractions of tropical grasses. Journal Animal Science, 79: 2439-2448, 2001.

Mayne, C. S.; Wright, I. A; Fesher, G. E. J. Grassland management under grazing and animal response. In: Hopkins, A. (Ed) Grass: its production \& utilization. Oxford: British, 2000, p.247-291.

Meyer, H. Alimentação de cavalos. São Paulo: Ed. Varela, 1995. 303p.

O'Reagain, P.J.; Schwartz, J. Dietary selection and foraging strategies of animals on rangeland. Coping with spatial and temporal variability. In: International Symposium on the nutrition of herbivores, 4: 407-423, 1995.

Resende, M.J.M.; Mcmanus, C.; Paludo, R.G.; Martins, R.D.; Oliveira, L.P.G.; Fuck, B. H.; Louvandini, H. Comportamento de cavalos das raças Bretã e Percheron estabulados. Ciência Animal Brasileira, 7: 17-25, 2006.

Santos, E.M.; Zanine, A.M.; Parente, H.N; Ferreira, D.J.; Almeida, F.Q.A.; Cecon, P.R. Comportamento ingestivo de eqüinos em pastagens de grama batatais (Paspalum notatum) e braquiarinha (Brachiaria decumbens) na região centro-oeste do Brasil. Ciência Rural, 36(5): 1565-1569, 2006.

Silva, M.S.J.; Lima, R.S.; Silva, M.J.S.; Lucena, J.E.C.; Carneiro, G.F.; Nascimento, W.G.; Jobim, C.J. Avaliação comportamental de éguas estabuladas em período reprodutivo. Revista de Ciências Agroveterinárias,14(1): 46-54, 2015.

Vieira, B.R.; Zanine, A.M.; Ferreira, D.J.; Vieira, A.J.M.; Cecon, P.R. Diferenças entre sexos para as atividades de pastejo de eqüinos no Extremo-Sul da Bahia. Revista Brasileira de Saúde e Produção Animal, 7(2): 103-111, 2006.

Waring, E.S.E. The behaviour of horses. In: Hafez, E.S.E. The behaviour of domestic animals, $3^{\text {rd }}$ ed. Cordon: Bailliere Tindall, 1975.

Zanine, A.M.; Santos, E.M.; Parente, H.N.; Ferreira, D.F.; Almeida, F.Q. Diferenças entre sexos para as atividades de pastejo de equinos no nordeste do Brasil. Archivos de Zootecnia, 55(210): 139-147, 2006.

Zanine, A.M.; Vieira, B.R.; Ferreira, D.J.; Vieira, A.J.M.; Lana, R.P. Comparação do hábito alimentar de eqüídeos sob pastejo. Archivos de Zootecnia, 58(223): 459-462, 2009. 